\title{
Functional decline in older patients with cancer receiving chemotherapy: A multicenter prospective study
}

\author{
Cindy Kenis ${ }^{\mathrm{a}, \mathrm{d}}$, Lore Decoster ${ }^{\mathrm{b}}$, Julie Bastin ${ }^{\mathrm{a}}$, Hannelore Bode ${ }^{\mathrm{a}}$, Katrien Van Puyvelde ${ }^{\mathrm{c}}$, Jacques De Grève ${ }^{\mathrm{b}}$, \\ Godelieve Conings $^{\mathrm{b}}$, Katleen Fagard ${ }^{\mathrm{d}}$, Johan Flamaing ${ }^{\mathrm{d}, \mathrm{e}}$, Koen Milisen ${ }^{\mathrm{d}, \mathrm{f}}$, \\ Jean-Pierre Lobelle ${ }^{\mathrm{g}}$, Hans Wildiers ${ }^{\mathrm{a}, \mathrm{h}, *}$ \\ a Department of General Medical Oncology, University Hospitals Leuven, Leuven, Belgium \\ ${ }^{\mathrm{b}}$ Department of Medical Oncology, Oncologisch Centrum, Universitair Ziekenhuis Brussel, Vrije Universiteit Brussel, Brussels, Belgium \\ c Frailty in Ageing (FRIA) Research Group \&' Gerontology Department, Vrije Universiteit Brussel, Brussels, Belgium \\ ${ }^{d}$ Department of Geriatric Medicine, University Hospitals Leuven, Leuven, Belgium \\ e Department of Clinical and Experimental Medicine, KU Leuven, Belgium \\ ${ }^{f}$ Department of Public Health and Primary Care, Academic Centre for Nursing and Midwifery, KU Leuven, Belgium \\ g Consultant in Statistics, Beernem, Belgium \\ ${ }^{\text {h }}$ Department of Oncology, KU Leuven, Belgium
}

\section{A R T I C L E I N F O}

\section{Article history:}

Received 21 April 2016

Received in revised form 2 January 2017

Accepted 24 February 2017

Available online $\mathrm{xxxx}$

\section{Keywords:}

Cancer

Functional decline

Functional status

Older person

Geriatric assessment

Survival

\begin{abstract}
A B S T R A C T
Objectives: This study aims to evaluate the evolution of functional status (FS) 2 to 3 months after initiation of chemotherapy, to identify factors associated with functional decline during chemotherapy treatment and to investigate the prognostic value of functional decline for overall survival (OS).

Patients and methods: Patients $\geq 70$ years with a malignant tumor were included when chemotherapy was initiated. All patients underwent a geriatric assessment (GA) including FS measured by Activities of Daily Living (ADL) and Instrumental Activities of Daily Living (IADL). FS of patients was followed by repeating ADL and IADL to identify functional decline.

Results: From 10/2009 until 07/2011, 439 patients were included. At follow-up, ADL and IADL data were available for 387 patients. Functional decline in ADL and IADL was observed in $19.9 \%$ and $41.3 \%$ of the patients respectively. In multivariable logistic regression analysis, baseline factors associated with decline in ADL are abnormal nutritional status (OR:2.02) and IADL dependency (OR:1.76). Oncological setting (disease progression/relapse vs new diagnosis) (OR:0.59) is the only determinant of decline in IADL. Functional decline in ADL is strongly prognostic for OS (logrank p-value <.0001; Wilcoxon p-value <.0001) with HR 2.34 and functional decline in IADL is also prognostic for OS but less prominent with HR 1.25.

Conclusions: Functional decline occurs in about a third of older patients with cancer receiving chemotherapy and is associated with GA components. It strongly predicts survival, the most prominent for ADL. This knowledge can be used to identify older persons with cancer receiving chemotherapy eligible for interventions to prevent functional decline.
\end{abstract}

(C) 2017 Elsevier Ltd. All rights reserved.

\footnotetext{
* Corresponding author at: Department of General Medical Oncology, University Hospitals Leuven, Herestraat 49, 3000, Leuven, Belgium. Tel.: +32 163469 20; fax: + 3216346901 .

E-mail addresses: cindy.kenis@uzleuven.be (C. Kenis), lore.decoster@uzbrussel.be (L. Decoster), julie_bastin@hotmail.com (J. Bastin), hannelore.bode@gmail.com (H. Bode), katrien.vanpuyvelde@asz.be (K. Van Puyvelde), jacques.degreve@uzbrussel.be (J. De Grève),godelieve.conings@uzbrussel.be (G. Conings), katleen.fagard@uzleuven.be (K. Fagard), johan.flamaing@uzleuven.be (J. Flamaing), koen.milisen@kuleuven.be (K. Milisen), jeanpierre.lobelle@gmail.com (J.-P. Lobelle), hans.wildiers@uzleuven.be (H. Wildiers)
}

\section{Introduction}

Maintenance of functional status (FS) is a key issue for older persons, certainly for those diagnosed with cancer [1]. Functional impairment has been independently associated with increased comorbidities [2] and shorter survival [3] and can lead to higher dependency, institutionalisation, and decreased quality of life [3,4]. 'Oncological' tools like the Karnofsky [5] or Eastern Cooperative Oncology group Performance Status (ECOG-PS) [6] scales reflect FS in a very simplistic way, and were not specifically developed and validated in the older population [1,7]. More sophisticated and age-adapted tools used in geriatric medicine are Katz's Activities of Daily Living (ADL) scale [8] and Lawton's Instrumental Activities of Daily Living (IADL) scale [9]. 
The assessment of FS is an integral part of the comprehensive geriatric assessment (CGA) which is the cornerstone of current geriatric medicine [10], and also recommended by the International Society of Geriatric Oncology (SIOG) and the European Organisation for Research and Treatment of Cancer (EORTC) in the care for older patients with cancer [7,11]. CGA is defined as a multidimensional, interdisciplinary diagnostic process focusing on determining an older person's medical, psychosocial, and functional capabilities to develop a coordinated and integrated plan for treatment and long-term follow-up [12].

Repeated assessment of FS over time gives treating physicians the opportunity to identify functional decline, which is a major threat for older persons in general [13] with increased risk for hospital and nursing home admission and mortality [14-16]. Functional decline is becoming an important health care focus for older patients in general during cancer treatment and more specific for older patients receiving chemotherapy $[17,18]$. In older patients receiving chemotherapy, the treatment is considered as a strong stressor that will reveal which patients have sufficient functional reserve to maintain functioning $[19,20]$.

While the number of older patients with cancer is expected to increase [21,22], little is known about the evolution of FS during chemotherapy treatment. A better understanding of this evolution may allow the possibility to predict functional decline which is crucial because it could allow preventive measures for patients at risk $[1,10,23]$.

Therefore, the aim of this study is to evaluate the evolution of FS in older patients with cancer 2 to 3 months after initiation of chemotherapy, to identify factors associated with functional decline during chemotherapy treatment and to investigate the prognostic value of functional impairments/decline for overall survival (OS).

\section{Patients and methods}

\subsection{Patient population}

The patient population in the current study has been described in detail elsewhere [24]. In summary, this was a prospective, noninterventional cohort study, performed in two academic hospitals in Belgium from October 2009 till July 2011. Patients 70 years and older with a malignant tumor, were approached for inclusion during a hospital visit by a trained nurse at diagnosis or at disease progression/relapse, when a cancer treatment decision had to be made. Disease progression/ relapse was defined as progression under treatment or relapse after a treatment free interval. Inclusion was limited to six tumor types: breast, colorectal, ovarian, lung, prostate cancer and hematologic malignancies. The study was approved by the Ethical Committee of both participating hospitals (University Hospitals Leuven and University Hospital Brussel; B32220096771) and written informed consent was obtained from all patients or their caregiver prior to enrolment in the study. For the present study, we performed a subanalysis on the patients receiving chemotherapy.

\subsection{Geriatric screening and assessment}

A geriatric screening and assessment was performed in all patients by a trained nurse at baseline [24]. In brief, geriatric screening was performed by the Flemish version of the Triage Risk Screening Tool (fTRST) ( $\geq 1$ is abnormal) [24-26] and G8 ( $\leq 14$ is abnormal) [24,27,28]. The geriatric assessment (GA) comprised demographic and social data, such as age (categorized in 70-74/75-79/ $\geq 80$ ), gender and living situation (living alone versus living with help).

Functional status (FS) was evaluated using Katz's Activities of Daily Living (ADL) scale [8] and Lawton's Instrumental Activities of Daily Living (IADL) scale [9]. The Katz scale includes six items (bathing, dressing, toileting, transferring, continence and feeding), with a score for each item ranging from one (able to perform the activity) to four (unable to perform the activity). Total score ranged from 6 (fully independent; no impairments) to 24 (fully dependent; 6 impairments) with dependency in ADL defined as a score of $>6$. The Lawton scale includes eight items (ability to use the telephone, shopping, cooking, housekeeping, doing laundry, responsibility of own medication, mode of transportation and ability to handle finances), with a score for each item of zero (low function, dependent, impairment) or one (high function, independent, no impairment). Because some of these items (cooking, housekeeping and doing laundry) are mostly done by women, these three items were not assessed in males in the original form, so the total score ranged from zero to five for men and from zero to eight for women. Consequently, dependency in IADL is defined as a score of $<5$ (male) or $<8$ (female).

Fall history was evaluated by asking the number of falls and fallrelated injuries in the past 12 months (presence of falls vs absence) $[29,30]$. Cognition was evaluated using the Mini Mental State Examination (MMSE) ( $<24$ is abnormal) [31] and risk for depression by the 15-item Geriatric Depression Scale (GDS-15) ( $\geq 5$ is abnormal) [32]. Nutritional status was assessed using the Mini Nutritional AssessmentShort Form (MNA-SF) ( $\leq 11$ is abnormal) $[33,34]$. The Charlson Comorbidity Index (CCI) ( $\geq 1$ is abnormal) [35] was used to describe the comorbidities. Self-perceived fatigue was assessed using the Mobility-Tiredness Test (Mob-T) (presence of fatigue is abnormal) [36] and pain was evaluated with the Visual Analogue Scale (VAS) ( $\geq 1$ is abnormal) [37]. Classical oncological parameters such as Eastern Cooperative Oncology Group - Performance Status (ECOG-PS) (categorized in 0-1 vs 2-4) [6], tumor characteristics (type and stage) and treatment details (presence of surgery/radiotherapy) were recorded. The number of drugs (www. bcfi.be) taken during the week before inclusion was recorded to detect polypharmacy ( $\geq 5$ different drugs).

\subsection{Functional decline and survival}

FS of patients was followed by repeating ADL and IADL two to three months after initiation of chemotherapy. A questionnaire was sent to the patient, asking to report the current situation in these domains. When the questionnaire didn't return, patients were contacted by telephone or contacted in the hospital in person to complete the follow-up data. Functional decline in ADL was defined as an increase of two or more points on the total score and in IADL as a decrease of one or more points on the total score $[23,24,38,39]$. Secondly, the evolution of FS was evaluated for all individual ADL and IADL items. An increase of one or more points on an individual ADL item or a decrease in one or more points in an individual IADL item was considered as functional decline. Survival data were collected for all patients included in February 2016.

\subsection{Statistical analysis}

All analyses were performed with SAS v9.3. All statistical tests were two-sided. For continuous data, mean, standard deviation, median, 95\% confidence intervals and range were assessed. For categorical data, frequency was assessed as well as the $95 \%$ confidence interval.

Identification of factors associated with functional decline was performed for ADL and IADL separately by univariate logistic regressions. The following baseline categorical variables were used as defined above: age, living situation, fTRST, G8, oncological setting, FS by ADL and IADL, fall history, MMSE, GDS, MNA-SF, CCI, MOB-T, pain, ECOG-PS, polypharmacy, presence of surgery/radiotherapy.

Multivariable logistic regressions were conducted on functional decline in ADL and IADL separately, 2 to 3 months after initiation of chemotherapy, using stepwise variable selection and p-value to enter and stay in the model of 0.05 . Only the variables which were significant in the univariate setting were considered for the multivariable regressions. Odds ratio's with $95 \%$ confidence limits for the significant variables are reported. Multiple collinearity was investigated for the independent variables used in the regressions, with variance inflation factor (VIF's) calculations, and was not detected so not further discussed. 
OS, defined as the time from study entry until death (any cause) is described by Kaplan Meier plots and comparisons are made by logrank and Wilcoxon's test. Data were censored at the date of last contact. A Cox proportional hazard regression with functional decline in ADL and IADL separately as the independent variables, was conducted for the OS analysis with mature data. Proportional hazard assumption was verified by inspection of the Kaplan Meier plots and of the $\log [-\log$ (survival probability)] versus $\log$ (time) plots, and the curves in both plots were parallel. No further correction was needed. Secondly, a multivariable Cox regression analysis was performed with the following variables: age, tumor type, functional decline in ADL, functional decline in IADL, FS by ADL and IADL, living situation, fall history, fatigue by MOB-T, MMSE, GDS, MNA-SF, CCI and polypharmacy. Hazard ratio's with $95 \%$ confidence limits were calculated in both regressions.

\section{Results}

\subsection{Patient and clinical characteristics}

For participation in the study, 1056 patients were approached. Of these patients, 54 patients refused to participate and 65 patients did not meet the inclusion criteria (mostly not being progressive, no invasive tumor diagnosed or primary origin of the tumor different from the six selected tumor types). Written informed consent was given by 931 patients and six caregivers, resulting in 937 patients included, of which 439 received chemotherapy (Fig. 1). The median age was 75 years (range: 70-95), and 57.6\% were female. Hematologic malignancies were the most common diagnoses, accounting for $26.4 \%$ of the patients, followed by colorectal cancer (24.6\%) and breast cancer (23.7\%). Within the hematologic malignancies, non-Hodgkin lymphoma was the most common subtype (29.4\%). At the moment of inclusion in the study, $55.6 \%$ had a newly diagnosed cancer, whereas $44.4 \%$ had disease progression/relapse. Comorbidities were present in 231 patients: $26.4 \%(n=116)$ had score 1 and $26.2 \%(n=115)$ had score $\geq 2$ on the $\mathrm{CCI}$. The most common comorbidities were congestive heart failure ( $\mathrm{n}=73 ; 31.6 \%$ ), diabetes mellitus without complications $(\mathrm{n}=55$; $23.8 \%$ ), secondary malignancy ( $\mathrm{n}=51 ; 22.1 \%$ ), myocardial infarction $(\mathrm{n}=38 ; 16.5 \%)$ and chronic pulmonary disease $(\mathrm{n}=35 ; 15.2 \%)$. Further patient and clinical characteristics are listed in Table 1. At baseline 205 (46.7\%) patients reported dependency in ADL and 244 (55.6\%) patients in IADL. Further results of the geriatric screening and assessment are shown in Table 2.

\subsection{Evolution of functional status after initiation of chemotherapy}

Two to 3 months after initiation of chemotherapy, data of 387 patients receiving chemotherapy were available for ADL and IADL (88.1\%). In these patients functional decline in ADL was observed in 19.9\% of the patients and in IADL in $41.3 \%$ of the patients. The evolution of FS related to the baseline FS is described in Fig. 2. There was no significant difference between the baseline independent and the baseline dependent group for functional decline in $\operatorname{ADL}(\mathrm{p}=0.126)$ and $\operatorname{IADL}(\mathrm{p}=0.389)$.

Considering the individual ADL components, patients declined most on the activities bathing (17.3\%), dressing (17.3\%) and continence (15.8\%). Considering the individual IADL components, female older patients declined most on the activities cooking (28.1\%), mode of transportation (25.0\%) and shopping (23.7\%), and male older patients declined most on mode of transportation (21.4\%), shopping (20.1\%) and responsibility of own medication (17.6\%) (Table 3 ).

A more in depth analysis on functional decline related to tumor type (all patients) and staging of the tumor (for carcinoma patients only), integrating three categories of FS (improvement, stable, decline) shows that the highest rates of functional decline in ADL and IADL are present in patients with lung cancer (26.3\%; 52.6\% respectively) and ovarian cancer (30.2\%; $44.2 \%$ respectively), followed by patients with hematologic malignancies and breast cancer. The results of this analysis are displayed in detail in the appendix of this article (see Appendices A and B).

\subsection{Factors associated with functional decline in ADL and IADL}

Table 4 describes univariate and multivariable analysis of factors associated with functional decline in ADL and IADL in the group of patients receiving chemotherapy $(\mathrm{n}=387)$. Independent factors associated with functional decline in ADL were abnormal nutritional status measured by MNA-SF (OR:2.02; 95\%CI:1.10-3.71), and baseline dependency in IADL activities (OR:1.76; 95\%CI:1.03-2.99). Oncological setting (disease

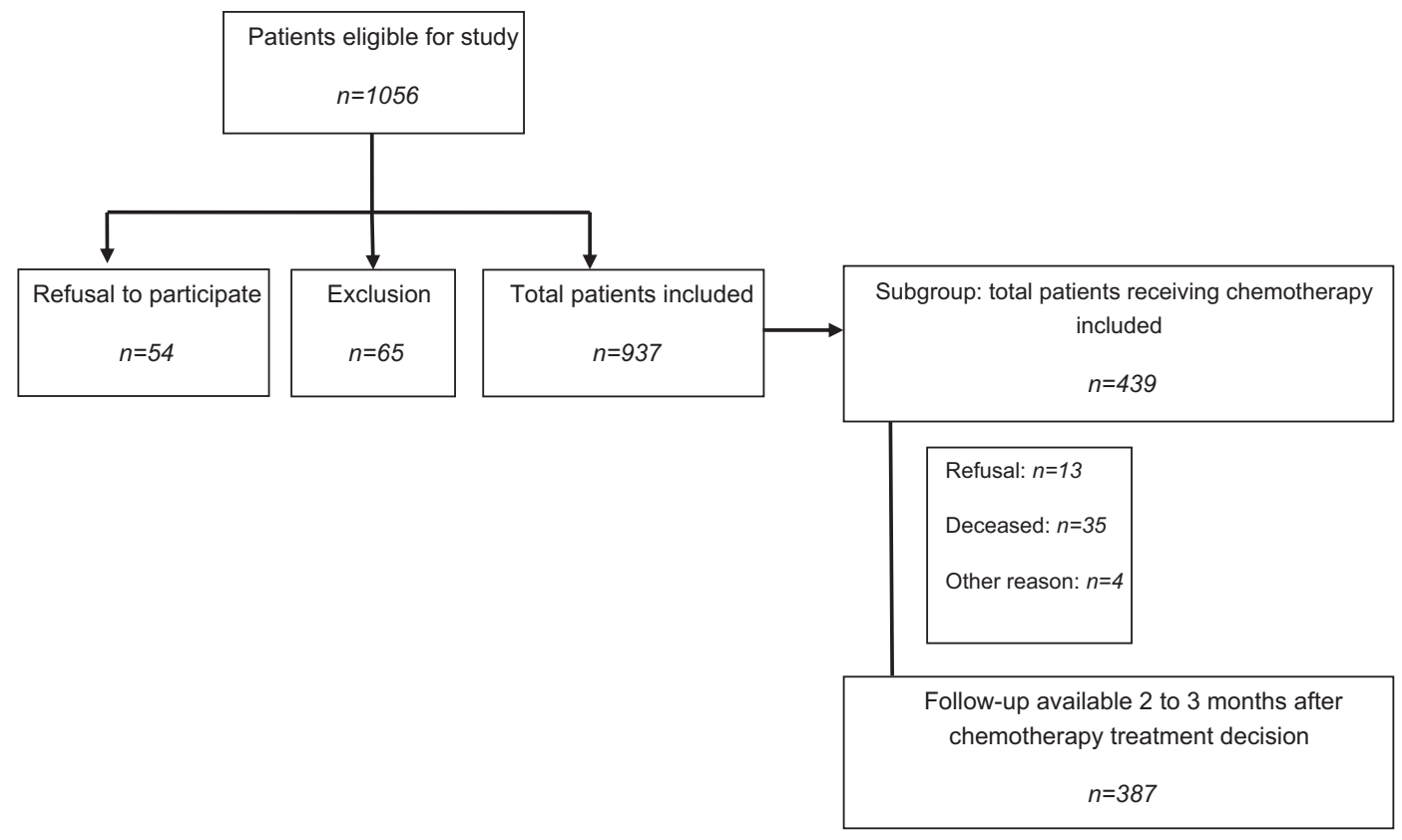

Fig. 1. Flow-chart of patient selection. 
Table 1

Patient and clinical characteristics.

\begin{tabular}{|c|c|c|c|c|c|c|}
\hline \multirow{3}{*}{ Age, years (median(range)) } & & & \multicolumn{4}{|c|}{ Patients receiving chemotherapy } \\
\hline & & & \multirow[t]{2}{*}{$\mathrm{n}=439$} & \multicolumn{3}{|c|}{$75(70-95)$} \\
\hline & & & & $\mathrm{n}$ & $\%$ & $95 \% \mathrm{CI}$ \\
\hline \multirow[t]{2}{*}{ Gender } & - Female & & $\mathrm{n}=439$ & 253 & 57.6 & $53.0-62.3$ \\
\hline & - Male & & & 186 & 42.4 & $37.7-47.0$ \\
\hline \multirow[t]{6}{*}{ Tumor type } & - Carcinoma & - Breast & $\mathrm{n}=439$ & 104 & 23.7 & $19.7-27.7$ \\
\hline & & - Colorectal & & 108 & 24.6 & $20.6-28.6$ \\
\hline & & - Lung & & 44 & 10.0 & $7.2-12.8$ \\
\hline & & - Ovarian & & 48 & 10.9 & $8.0-13.9$ \\
\hline & & - Prostate & & 19 & 4.3 & $2.4-6.2$ \\
\hline & - Hematologic malignancies & & & 116 & 26.4 & $22.3-30.5$ \\
\hline \multirow[t]{2}{*}{ Oncological setting } & - New diagnosis & & $\mathrm{n}=439$ & 244 & 55.6 & $50.9-60.2$ \\
\hline & - At disease progression/relapse & & & 195 & 44.4 & $39.8-49.1$ \\
\hline \multirow[t]{8}{*}{ Carcinoma } & - Stage & $-I$ & $\mathrm{n}=323$ & 5 & 1.5 & $0.2-2.9$ \\
\hline & & - II & & 34 & 10.5 & $7.2-13.9$ \\
\hline & & - III & & 62 & 19.2 & $14.9-23.5$ \\
\hline & & - IV & & 222 & 68.7 & $63.7-73.8$ \\
\hline & - Treatment received ${ }^{\mathrm{a}}$ & - Surgery & & 107 & 33.1 & $28.0-38.3$ \\
\hline & & - Chemotherapy & & 323 & 100.0 & $100-100$ \\
\hline & & - Radiotherapy & & 60 & 18.6 & $14.3-22.8$ \\
\hline & & - Hormonal therapy & & 29 & 9.0 & $5.9-12.1$ \\
\hline \multirow[t]{5}{*}{ Hematologic malignancies } & - Setting & - Curative & $\mathrm{n}=116$ & 45 & 38.8 & $29.9-47.7$ \\
\hline & & - Palliative & & 71 & 61.2 & $52.3-70.1$ \\
\hline & - Treatment received ${ }^{\mathrm{a}}$ & - Surgery & & 0 & 0.0 & $0-0$ \\
\hline & & - Chemotherapy & & 116 & 100.0 & $100-100$ \\
\hline & & - Radiotherapy & & 3 & 2.6 & $0-5.5$ \\
\hline \multirow[t]{3}{*}{ Comorbidity } & CCI $(0-37)$ & - No comorbidities (score 0 ) & $\mathrm{n}=439$ & 208 & 47.4 & $42.7-52.1$ \\
\hline & & - Comorbidity score 1 & & 116 & 26.4 & $22.3-30.5$ \\
\hline & & - Comorbidity score $\geq 2$ & & 115 & 26.2 & $22.1-30.3$ \\
\hline \multirow[t]{2}{*}{ Performance status } & ECOG-PS (0-5) & - Score 0 -1 & $\mathrm{n}=439$ & 330 & 75.2 & $71.1-79.2$ \\
\hline & & - Score 2-4 & & 109 & 24.8 & $20.8-28.9$ \\
\hline \multirow[t]{3}{*}{ Pain } & VAS $(0-10)$ & - No pain: score $=0$ & $\mathrm{n}=438$ & 205 & 46.8 & $42.1-51.5$ \\
\hline & & - Mild pain: score $=1-3$ & & 69 & 15.8 & $12.3-19.2$ \\
\hline & & - Pain to treat: score $\geq 4$ & & 164 & 37.4 & $32.9-42.0$ \\
\hline \multirow[t]{2}{*}{ Polypharmacy } & & - 0-4 different drugs & $\mathrm{n}=427$ & 220 & 51.5 & $46.8-56.3$ \\
\hline & & $-\geq 5$ different drugs & & 207 & 48.5 & $43.7-53.2$ \\
\hline
\end{tabular}

Legend: $\mathrm{CI}=$ confidence interval; $\mathrm{CCI}=$ Charlson Comorbidity Index; ECOG PS = Eastern Cooperative Oncology Group Performance Status; VAS = Visual Analogue Scale.

a Treatment received $=$ patients may have received a combination of treatment modalities.

Table 2

Results of the baseline geriatric screening and assessment.

\begin{tabular}{|c|c|c|c|c|c|c|}
\hline \multirow[b]{2}{*}{ Screening } & \multirow[b]{2}{*}{ Cut-off } & \multirow[b]{2}{*}{ Score } & \multicolumn{4}{|c|}{ Patients receiving chemotherapy } \\
\hline & & & & $\mathrm{n}$ & $\%$ & $95 \% \mathrm{CI}$ \\
\hline \multirow[t]{2}{*}{ fTRST $(0-6)$} & $\geq 1$ & - Absence of a geriatric risk profile: score 0 & $\mathrm{n}=439$ & 85 & 19.4 & $15.7-23.1$ \\
\hline & & - Presence of a geriatric risk profile: score $\geq 1$ & & 354 & 80.6 & $76.9-84.3$ \\
\hline \multirow[t]{2}{*}{ G8 (0-17) } & $\leq 14$ & - Absence of a geriatric risk profile: score $>14$ & $\mathrm{n}=439$ & 110 & 25.1 & $21.0-29.1$ \\
\hline & & - Presence of a geriatric risk profile: score $\leq 14$ & & 329 & 74.9 & $70.9-79.0$ \\
\hline GA & Item/instrument & Score & & $\mathrm{n}$ & $\%$ & $95 \% \mathrm{CI}$ \\
\hline \multirow[t]{2}{*}{ Social data } & Living situation & - Living alone & $\mathrm{n}=439$ & 117 & 26.7 & $22.5-30.8$ \\
\hline & & - Living with help & & 322 & 73.3 & $69.2-77.5$ \\
\hline \multirow[t]{6}{*}{ Functional status } & ADL (6-24) & - Independent: score 6 & $\mathrm{n}=439$ & 234 & 53.3 & $48.6-58.0$ \\
\hline & & - Dependent: score $\geq 7$ & & 205 & 46.7 & $42.0-51.4$ \\
\hline & IADL $(0-5 / 8)$ & - Independent: score 8 (female) or 5 (male) & $\mathrm{n}=439$ & 195 & 44.4 & $39.8-49.1$ \\
\hline & & - Dependent: score $<8$ (female) or 5 (male) & & 244 & 55.6 & $50.9-60.2$ \\
\hline & Fall history in the past 12 months & - No falls & $\mathrm{n}=439$ & 321 & 73.1 & $69.0-77.3$ \\
\hline & & $-\geq 1$ fall & & 118 & 26.9 & $22.7-31.0$ \\
\hline \multirow[t]{2}{*}{ Fatigue } & MOB-T & - No fatigue & $\mathrm{n}=439$ & 168 & 38.3 & $33.7-42.8$ \\
\hline & $(0-6)$ & - Presence of fatigue & & 271 & 61.7 & $57.2-66.3$ \\
\hline \multirow[t]{2}{*}{ Cognition } & MMSE & - Score $\geq 24=$ normal cognition & $\mathrm{n}=438$ & 412 & 94.1 & $91.9-96.3$ \\
\hline & $(0-30)$ & - Score $\leq 23=\mathrm{mild} /$ severe cognitive decline & & 26 & 5.9 & $3.7-8.1$ \\
\hline \multirow[t]{2}{*}{ Depression } & GDS-15 & - Score $0-4=$ not at risk for depression & $\mathrm{n}=437$ & 347 & 79.4 & $75.6-83.2$ \\
\hline & $(0-15)$ & - Score $5-15=$ at risk for depression & & 90 & 20.6 & $16.8-24.4$ \\
\hline \multirow[t]{3}{*}{ Nutrition } & MNA-SF & - Score $\geq 12=$ normal nutritional status & $\mathrm{n}=439$ & 139 & 31.7 & $27.3-36.0$ \\
\hline & $(0-14)$ & - Score $8-11=$ risk of malnutrition & & 206 & 46.9 & $42.3-51.6$ \\
\hline & & - Score $\leq 7=$ malnourished & & 94 & 21.4 & $17.6-25.2$ \\
\hline
\end{tabular}

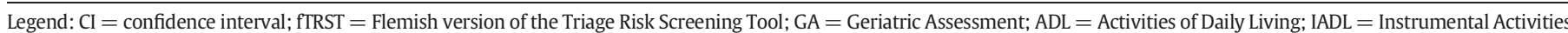
of Daily Living; MOB-T = Mobility - Tiredness Test; MMSE = Mini Mental State Examination; GDS = Geriatric Depression Scale; MNA-SF = Mini Nutritional Assessment - Short Form. 


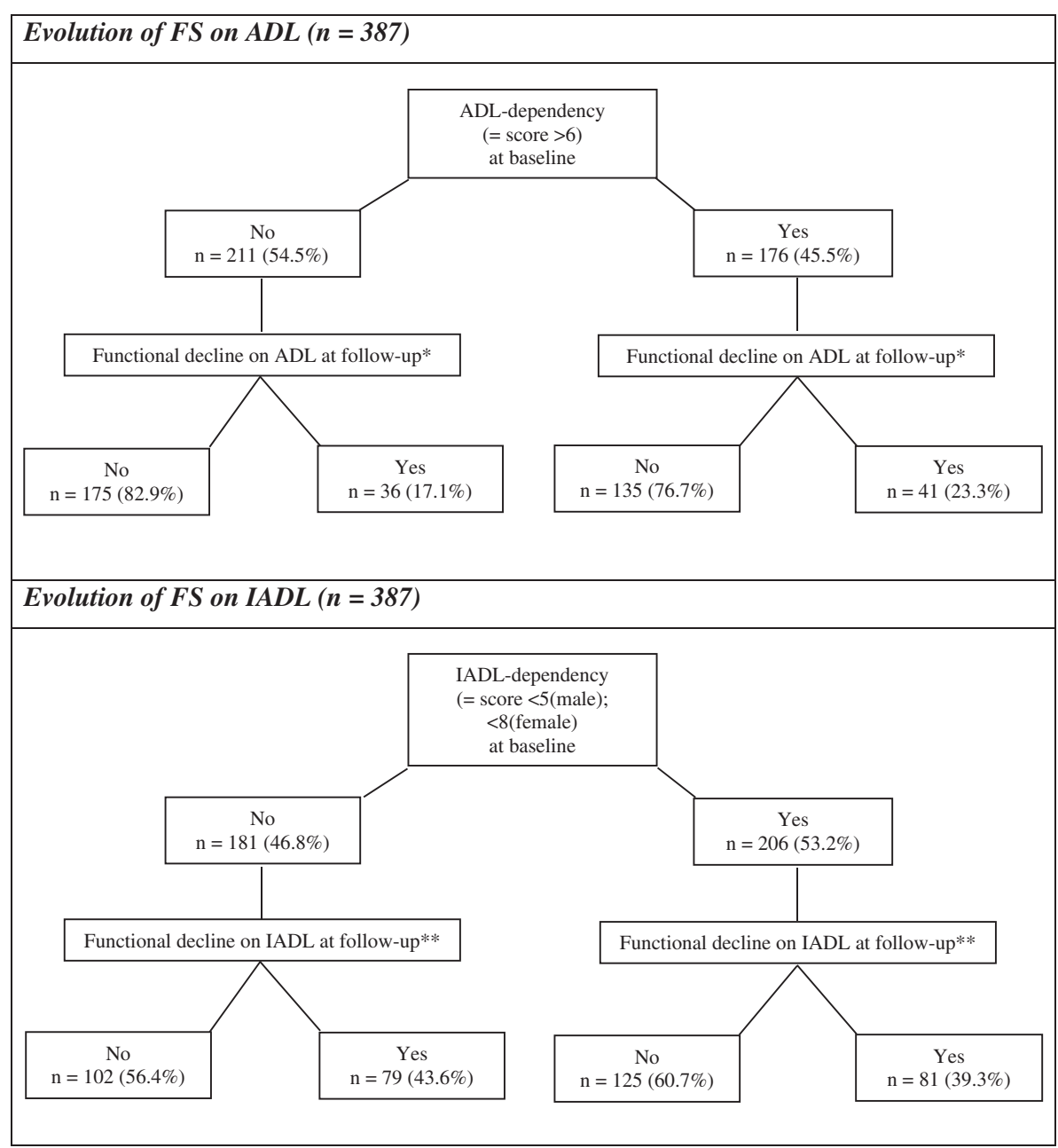

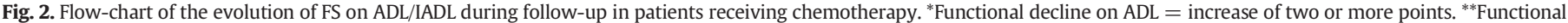
decline on IADL = decrease of one or more points. Legend: FS: Functional Status; ADL: Activities of Daily Living; IADL: Instrumental Activities of Daily Living.

progression/relapse vs new diagnosis) (OR:0.59; 95\%CI: 0.39-0.90) was the only factor associated with functional decline in IADL.

3.4. Prognostic value of functional impairment/decline in $A D L / I A D L$ for overall survival

At the time of data analysis (February 2016), the median survival time was 21.1 months (95\%CI: 17.45-26.38; range: $0.1-75.72 ; \mathrm{n}=$ 439 ), and $72 \%$ of the patients had died. Baseline FS measured by ADL and IADL (dependent versus independent) were both prognostic for OS with logrank p-value 0.009 and 0.003 respectively $(n=439)$.

Functional decline in ADL showed a strong prognostic value for OS (logrank p-value $<0.0001$; Wilcoxon p-value $<0.0001$ ) (see Fig. 3). Functional decline in IADL also showed a prognostic value for OS (logrank p-value 0.100; Wilcoxon p-value 0.043) (see Fig. 3). However, functional decline in ADL had much higher discriminatory power than decline in IADL as suggested by higher HR for OS: HR for ADL (decline versus no decline) was 2.34 (95\% CI 1.75-3.12) and for IADL (decline versus no decline) 1.25 (95\% CI 0.97-1.61).

In the multivariable Cox regression analysis factors that showed a strong prognostic capacity for OS were: functional decline in ADL, tumor type, MNA-SF and baseline FS by ADL (p-value: $<0.0001,<0.0001$; 0.004 and 0.010 respectively). The highest discriminatory power were for functional decline in ADL (HR 2.44; 95\%CI 1.80-3.31), and for the following combinations with tumor type 'lung versus hematologic malignancy' and 'lung versus ovarian' with HR 3.11 (95\%CI 1.96-4.93) and 2.79 (95\%Cl 1.66-4.68) respectively (see Table 5).

\section{Discussion}

In contrast to many previous studies describing baseline FS in older cancer populations [7,24,40-46], this prospective multicenter study focuses on evolution of FS in patients receiving chemotherapy (functional decline versus stable/improvement). Moreover factors associated with functional decline in older ( $\geq 70$ years) patients with cancer receiving chemotherapy were studied.

Our results show that older patients with cancer receiving chemotherapy experience a significant decline in functional capabilities, as indicated by the presence of functional decline in ADL and IADL in 19.9\% and $41.3 \%$ respectively. This means that older people more often lose IADL than ADL related capacities 2 to 3 months after initiation of chemotherapy. This is understandable, since ADL measures basic functions required to maintain independence at home, while IADL evaluates more complex activities that require cognitive functions necessary to maintain independence [9]. So, they first lose the more complex functions, and to a lesser extent the more basic functions.

Studies describing the evolution of FS and more specifically functional decline in older patients with cancer are scarce and only appeared recently in the literature, which hampers the comparison of our results with other studies. A few other studies have investigated the evolution of FS in older patients with cancer [19,47-49]. 
Table 3

Functional decline on the individual items of ADL and IADL in patients receiving chemotherapy.

\begin{tabular}{|c|c|c|c|c|c|c|}
\hline \multirow[b]{2}{*}{$\begin{array}{l}\text { Functional } \\
\text { status }\end{array}$} & & \multirow[b]{2}{*}{$\begin{array}{l}\text { Functional decline at } \\
2-3 \text { months on individual } \\
\text { items }{ }^{\mathrm{a}}\end{array}$} & \multicolumn{4}{|c|}{ Patients receiving chemotherapy } \\
\hline & & & & $\mathrm{n}$ & $\%$ & $95 \% \mathrm{CI}$ \\
\hline \multirow[t]{6}{*}{ ADL } & & - Bathing & $\mathrm{n}=387$ & 67 & 17.3 & $13.5-21.1$ \\
\hline & & - Dressing & & 67 & 17.3 & $13.5-21.1$ \\
\hline & & - Toilette & & 45 & 11.6 & $8.4-14.8$ \\
\hline & & - Transfer & & 32 & 8.3 & $5.5-11.0$ \\
\hline & & - Continence & & 61 & 15.8 & $12.1-19.4$ \\
\hline & & - Feeding & & 26 & 6.7 & $4.2-9.2$ \\
\hline \multirow[t]{13}{*}{ IADL } & - Female & - Ability to use telephone & $\mathrm{n}=228$ & 3 & 1.3 & $0-2.8$ \\
\hline & & - Shopping & & 54 & 23.7 & $18.2-29.2$ \\
\hline & & - Cooking & & 64 & 28.1 & $22.2-33.9$ \\
\hline & & - Housekeeping & & 26 & 11.4 & $7.3-15.5$ \\
\hline & & - Laundry & & 43 & 18.9 & $13.8-23.9$ \\
\hline & & - Mode of transportation & & 57 & 25.0 & $19.4-30.6$ \\
\hline & & $\begin{array}{l}\text { - Responsibility of own } \\
\text { medication }\end{array}$ & & 28 & 12.3 & $8.0-16.5$ \\
\hline & & - Ability to handle finances & & 23 & 10.1 & $6.2-14.0$ \\
\hline & - Male & - Ability to use telephone & $\mathrm{n}=159$ & 5 & 3.1 & $0.4-5.9$ \\
\hline & & - Shopping & & 32 & 20.1 & $13.9-26.4$ \\
\hline & & - Mode of transportation & & 34 & 21.4 & $15.0-27.8$ \\
\hline & & $\begin{array}{l}\text { - Responsibility of own } \\
\text { medication }\end{array}$ & & 28 & 17.6 & $11.7-23.5$ \\
\hline & & - Ability to handle finances & & 17 & 10.7 & $5.9-15.5$ \\
\hline
\end{tabular}

Legend: $\mathrm{CI}=$ confidence interval; $\mathrm{ADL}=$ Activities of Daily Living; $\mathrm{IADL}=$ Instrumental Activities of Daily Living.

a Functional decline on individual items on ADL is defined as an increase of one or more points. Functional decline on individual items on IADL is defined as a decrease of one point

The study of Puts et al. focused on older patients with newlydiagnosed cancer ( $\mathrm{n}=112$; both solid tumors and hematologic malignancies). They included all types of cancer treatment, not only chemotherapy, and showed that $22.0 \%$ of patients experienced functional decline during a six-month follow-up period, not mentioning the results separately for decline in ADL and IADL [19]. Another study, focusing on one year follow-up, describes the presence of functional decline in $58 \%$ of older patients with cancer ( $\mathrm{n}=134$; breast and colorectal cancer, stage I-III), again not reporting the results separately for ADL and IADL [49]. The study of Hoppe et al. is focusing on older patients with cancer receiving first-line chemotherapy ( $\mathrm{n}=364$; both solid tumors and nonHodgkin lymphoma) [47]. They report an observed functional decline in ADL in $16.7 \%$ which is slightly lower than in our study (19.9\%). This could be related to the fact that in our study patients received chemotherapy in any setting (not only first-line). In the study of Ronning et al., higher rates of functional decline are observed: $31 \%$ and $69 \%$ for ADL and IADL respectively $(\mathrm{n}=84)$ [48]. Probably the population studied (patients with colorectal cancer undergoing surgery) and the impact of surgery on function explains these high numbers, suggesting that the type of treatment has differential impact on FS.

Overall, these results confirm that functional decline occurs frequently during treatment of older patients with cancer. Nevertheless, it is difficult to draw firm conclusions, because of the differences between the studies concerning tumor types, settings, treatment modalities, follow-up period and measuring instruments used.

Additionally, we did not find any study in the literature describing the evolution of the individual ADL and IADL items after the initiation of chemotherapy. For ADL, we can conclude that the highest impact during chemotherapy treatment is on the items bathing, dressing and continence. For IADL, both female and male patients, the most prominent items for decline are shopping and mode of transportation. For female patients cooking should be added to this list.

Focus on the individual items is important for the development of prevention programs for functional decline and professional health care workers need to pay specific attention to these items to ensure that support can be given during treatment with chemotherapy.

Assessment of FS and determination of factors associated with functional decline are very useful to assist the treating physician in treatment decision making and in identification of individuals at high

Table 4

Factors associated with functional decline on ADL/IADL in patients receiving chemotherapy in univariate and multivariable analysis.

\begin{tabular}{|c|c|c|c|c|c|c|c|c|c|}
\hline \multirow[b]{3}{*}{ Variable } & \multirow[b]{3}{*}{ Categorisation } & \multicolumn{4}{|c|}{ Functional decline on ADL } & \multicolumn{4}{|c|}{ Functional decline on IADL } \\
\hline & & \multirow{2}{*}{$\frac{\text { Univariate }}{\text { p-Value }}$} & \multicolumn{3}{|c|}{ Multivariable } & \multirow{2}{*}{$\frac{\text { Univariate }}{\text { p-Value }}$} & \multicolumn{3}{|c|}{ Multivariable } \\
\hline & & & p-Value & OR & $95 \% \mathrm{CI}$ & & p-Value & OR & $95 \% \mathrm{Cl}$ \\
\hline Age & $70-74$ vs $75-79$ vs $\geq 80 y$ & 0.603 & & & & 0.593 & & & \\
\hline fTRST & Geriatric risk profile ( $\geq 1)$ vs no geriatric risk profile $(0)$ & 0.075 & & & & 0.349 & & & \\
\hline G8 & Geriatric risk profile $(\leq 14)$ vs no geriatric risk profile $(>14)$ & 0.026 & - & & & 0.210 & & & \\
\hline Oncological setting & Progression/relapse vs new diagnosis & 0.236 & & & & 0.014 & 0.014 & 0.59 & $0.39-0.90$ \\
\hline ECOG-PS & Score $2-4$ vs score $0-1$ & 0.020 & - & & & 0.220 & & & \\
\hline $\begin{array}{l}\text { Fall history in the past } \\
12 \text { months }\end{array}$ & Falls in the past 12 months vs no falls & 0.139 & & & & 0.877 & & & \\
\hline Pain & Mild pain/pain to treat vs no pain & 0.756 & & & & 0.865 & & & \\
\hline Polypharmacy & $\geq 5$ different drugs vs $0-4$ different drugs & 0.089 & & & & 0.147 & & & \\
\hline Living situation & Living alone vs living with help & 0.133 & & & & 0.108 & & & \\
\hline $\mathrm{CCI}$ & Comorbidities $(\geq 1)$ vs no comorbidities $(0)$ & 0.285 & & & & 0.938 & & & \\
\hline $\mathrm{ADL}$ & ADL dependent ( $\geq 7$ ) vs ADL independent (6) & 0.127 & & & & 0.961 & & & \\
\hline IADL & $\begin{array}{l}\text { IADL dependent }(\leq 4 \text { (male }) / 7 \text { (female) vs IADL independent } \\
(5(\text { male }) / 8 \text { (female }))\end{array}$ & 0.011 & 0.037 & 1.76 & $1.03-2.99$ & 0.389 & & & \\
\hline Fatigue by МOB-T & Presence of fatigue vs no fatigue & 0.030 & - & & & 0.081 & & & \\
\hline MMSE & Mild/severe cognitive decline $(\leq 23)$ vs normal cognition $(\geq 24)$ & 0.394 & & & & 0.089 & & & \\
\hline GDS-15 & At risk for depression $(\geq 5)$ vs not at risk $(0-4)$ & 0.261 & & & & 0.245 & & & \\
\hline MNA-SF & $\begin{array}{l}\text { Risk for malnutrition/malnourished }(\leq 11) \text { vs normal nutritional } \\
\text { status }(\geq 12)\end{array}$ & 0.008 & 0.007 & 2.02 & $1.10-3.71$ & 0.809 & & & \\
\hline Surgery & Surgery vs no surgery & 0.217 & & & & 0.370 & & & \\
\hline Radiotherapy & Radiotherapy vs no radiotherapy & 0.335 & & & & 0.031 & - & & \\
\hline Tumor type & $\begin{array}{l}\text { Breast vs colorectal vs prostate vs lung vs ovarian vs hematologic } \\
\text { malignancies }\end{array}$ & 0.271 & & & & 0.072 & & & \\
\hline
\end{tabular}

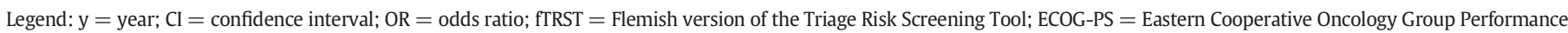

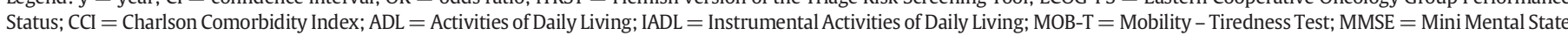
Examination; GDS-15 = 15 item Geriatric Depression Scale; MNA-SF = Mini Nutritional Assessment - Short Form; vs = versus. 


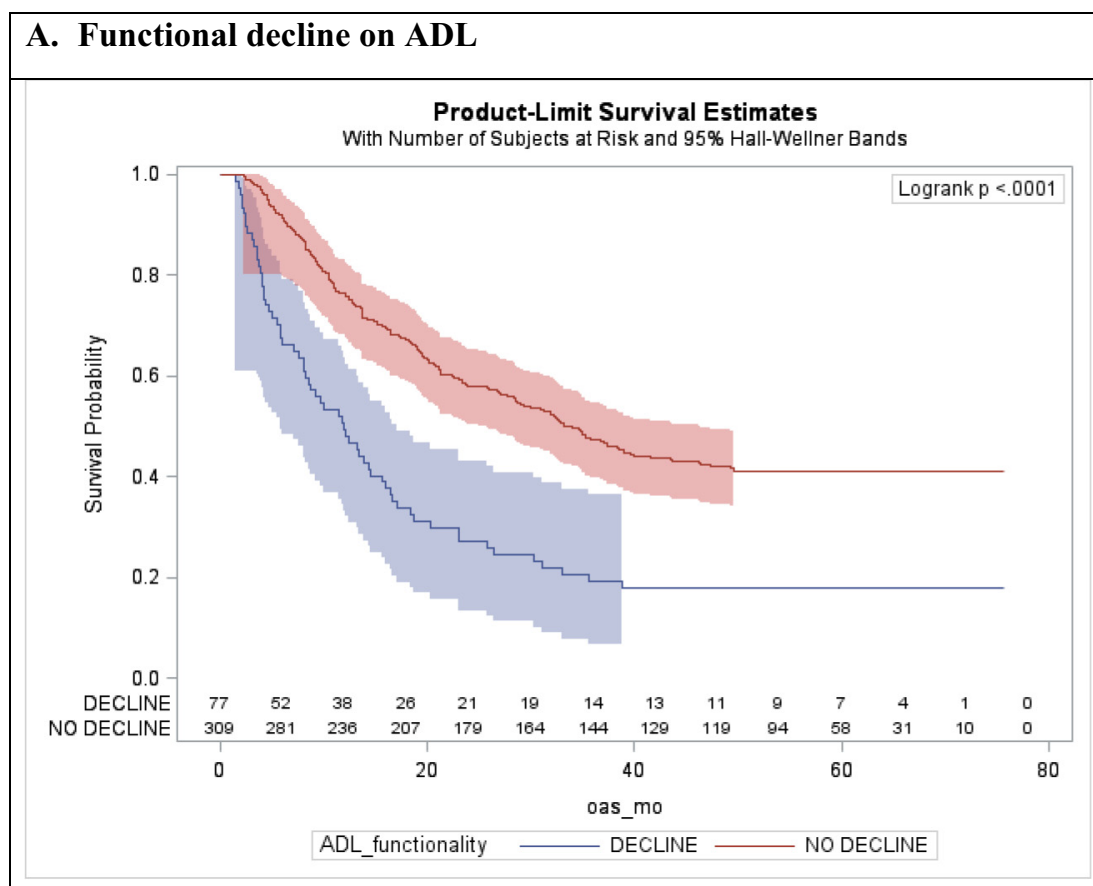

\section{B. Functional decline on IADL}

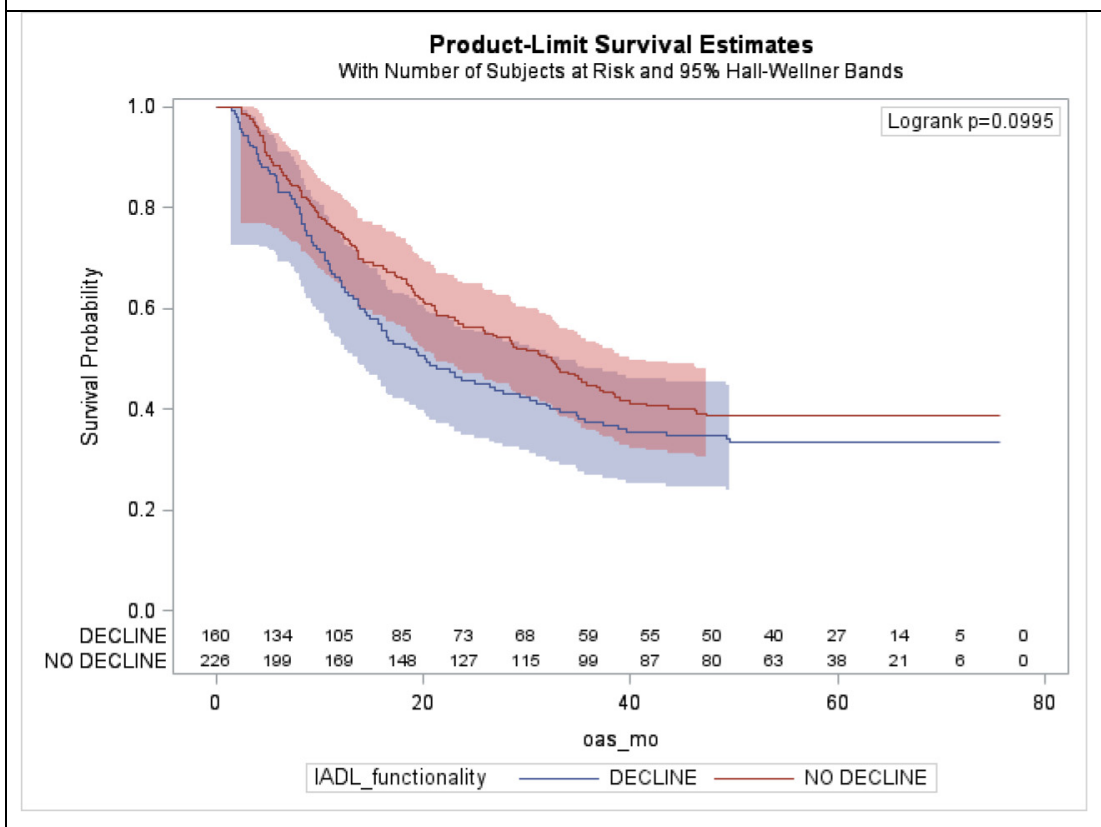

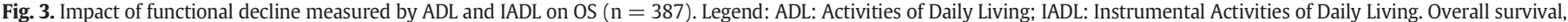

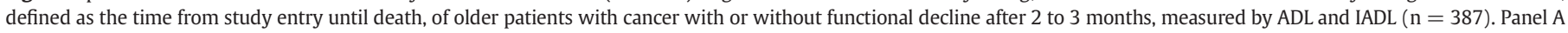

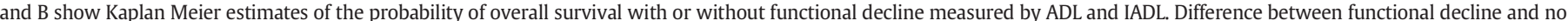

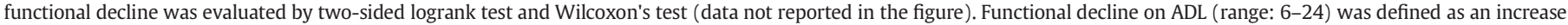

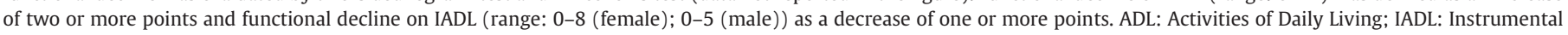
Activities of Daily Living.

risk for future disability. Several factors associated with functional decline in ADL and IADL were identified by multivariable analysis.

In our study we found that factors associated with functional decline in ADL were baseline IADL dependency and abnormal nutritional status (MNA-SF $\leq 11$ ). In the study of Hoppe et al. baseline IADL dependency was also a factor associated with functional decline in ADL [47]. This suggests that impairments in IADL before initiation of chemotherapy increase the risk of subsequent impairments on ADL. Another important factor associated with functional decline in ADL in our study is nutritional status, which is in accordance with other studies in the general older population [50,51]. The only factor associated with functional decline in IADL was the oncological setting (disease progression/relapse vs new diagnosis). Patients included with a new diagnosis seem to have more risk for functional decline in IADL than patients included at disease progression/relapse. This could be explained by the possibility that patients with disease progression/relapse already experienced functional decline during previous therapy.

Looking at the factors that were not associated with functional decline in ADL and IADL in our study, we can conclude that age is one of them. Hoppe et al. already stated that this factor in particular has been 
Table 5

Results of the multivariable Cox regression analysis for overall survival.

\begin{tabular}{|c|c|c|c|c|}
\hline Variable & & Logrank p-value & Hazard ratio & $95 \% \mathrm{CI}$ \\
\hline Functional decline in ADL & Decline vs no decline & $<0.0001$ & 2.44 & $1.80-3.31$ \\
\hline \multirow[t]{15}{*}{ Tumor type } & Breast vs lung & $<0.0001$ & 0.31 & $0.19-0.51$ \\
\hline & Breast vs colorectal & & 0.54 & $0.37-0.81$ \\
\hline & Breast vs ovarian & & 0.86 & $0.52-1.43$ \\
\hline & Breast vs prostate & & 0.38 & $0.21-0.70$ \\
\hline & Breast vs hematologic malignancy & & 0.97 & $0.63-1.49$ \\
\hline & Lung vs colorectal & & 1.75 & $1.14-2.70$ \\
\hline & Lung vs ovarian & & 2.79 & $1.66-4.68$ \\
\hline & Lung vs prostate & & 1.23 & $0.65-2.31$ \\
\hline & Lung vs hematologic malignancy & & 3.11 & $1.96-4.93$ \\
\hline & Colorectal vs ovarian & & 1.59 & $1.02-2.49$ \\
\hline & Colorectal vs prostate & & 0.70 & $0.40-1.24$ \\
\hline & Colorectal vs hematologic malignancy & & 1.78 & $1.22-2.58$ \\
\hline & Ovarian vs prostate & & 0.44 & $0.23-0.84$ \\
\hline & Ovarian vs hematologic malignancy & & 1.12 & $0.70-1.78$ \\
\hline & Prostate vs hematologic malignancy & & 2.54 & $1.41-4.58$ \\
\hline MNA-SF & Normal nutritional status $(\geq 12)$ vs at risk for malnutrition/malnourished $(\leq 11)$ & 0.004 & 0.65 & $0.48-0.89$ \\
\hline ADL & ADL independent $(6)$ vs ADL dependent $(\geq 7)$ & 0.010 & 0.71 & $0.54-0.92$ \\
\hline
\end{tabular}

Legend: $\mathrm{ADL}=$ Activities of Daily Living; MNA-SF = Mini Nutritional Assessment - Short Form; $\mathrm{CI}=$ confidence interval; vs = versus.

highlighted as an independent factor in studies in the general older population [47,52,53], but neither in the study of Hoppe et al. nor in our study this was observed in the older population with cancer. This supports the heterogeneity of the aging process and highlights the importance of the implementation of CGA including assessment of FS when treating older patients with cancer.

Secondly, it should be acknowledged that several factors associated with functional decline described in univariate analysis, were not identified as factors associated with functional decline in ADL or IADL in older patients with cancer by multivariable analysis in the current study, meaning that more factors are influencing functional decline but with smaller impact.

To our knowledge, the prognostic value of functional decline for OS in older patients with cancer, wether or not receiving chemotherapy, has not been studied before. Most but not all studies, identified baseline GA components as independent factors to predict OS [7] and baseline FS is one of the most consistent factors associated with OS in older patients with cancer, and more specifically IADL status. [7,44,45,54,55] This was also confirmed in our cohort with mature data. To determine the prognostic value of functional decline after the initiation of chemotherapy, we performed a Cox proportional hazard regression with functional decline in ADL and IADL separately as the independent variables, and a multivariable Cox regression. Functional decline in ADL and IADL at 2 to 3 months after initiation of chemotherapy were both prognostic for OS with the highest discriminatory power for functional decline in ADL. In the multivariable Cox regression functional decline in ADL had also the highest prognostic value for OS. Although older patients with cancer experience more frequently a functional decline in IADL, the effect of functional decline in ADL has a stronger impact on the general health status with higher mortality as consequence. Functional decline in ADL is thus less prevalent than IADL decline, but has more impact on survival. Additionally, we can also state that having impairments on IADL at baseline has more impact on OS than experiencing functional decline in IADL. The contrary is true for ADL dependency and functional decline in ADL.

This study has some limitations. First, there is no current consensus on the criteria to define functional decline related to the instrument that is used to measure ADL (e.g. Katz's scale or Barthel Index) and over which period it should be monitored $[23,49,56]$. Secondly, we included a quite heterogeneous population, where the setting (early versus advanced diseases), tumor type (6 tumor types with each type consisting of sometimes very different subtypes), and the choice of chemotherapy regimen can have different impact on FS, functional decline and OS. Strengths of the study are the fact that both ADL and IADL are integrated and investigated, the subanalysis of the individual components of these scales, the use of a prospective multicentric design and a low drop-out rate.

\section{Conclusions}

In conclusion, this study shows that functional decline occurs frequently in older patients with cancer receiving chemotherapy, and is even more pronounced for IADL than for ADL activities. GA components (IADL and MNA-SF) are identified as independent factors associated with functional decline in ADL during chemotherapy treatment. Functional decline in IADL was mainly seen in patients with a new cancer diagnosis. Additionally, functional decline, especially decline in ADL, has a strong prognostic value for OS. Focus on the individual ADL and IADL items should support the development and implementation of interventions preventing functional decline in patients at risk during chemotherapy treatment.

\section{Disclosures and conflict of interest statement}

The authors declare that they have no competing interests.

\section{Author contributions}

Study Concepts: C Kenis, L Decoster, Johan Flamaing, K Milisen, $\mathrm{H}$ Wildiers.

Study Design: C Kenis, L Decoster, J Bastin, H Bode, K Van Puyvelde, J De Grève, G Conings, K Fagard, Johan Flamaing, K Milisen, JP Lobelle, $\mathrm{H}$ Wildiers.

Data Acquisition: C Kenis, L Decoster.

Quality Control of Data and Algorithms: C Kenis, L Decoster, JP Lobelle, H Wildiers.

Data Analysis and Interpretation: C Kenis, L Decoster, Johan Flamaing, K Milisen, JP Lobelle, H Wildiers.

Statistical Analysis: JP Lobelle.

Manuscript Preparation: C Kenis, H Wildiers.

Manuscript Editing: C Kenis, L Decoster, J Bastin, H Bode, K Van Puyvelde, J De Grève, G Conings, K Fagard, Johan Flamaing, K Milisen, JP Lobelle, H Wildiers.

Manuscript Review: C Kenis, L Decoster, J Bastin, H Bode, K Van Puyvelde, J De Grève, G Conings, K Fagard, Johan Flamaing, K Milisen, JP Lobelle, H Wildiers.

\section{Funding}

This work was supported by the 'Vlaamse Liga tegen Kanker'. 


\section{Acknowledgements}

The authors would like to thank all the patients, trained nurses and treating physicians in both centres. We also thank 'Kom op tegen Kanker (KotK)' for grant support.

HW is a recipient of a grant of the 'Fonds Voor Wetenschappelijk Onderzoek Vlaanderen'.

\section{Appendix A. Evolution of functional status related to tumor type}

\begin{tabular}{|c|c|c|c|}
\hline & \multicolumn{3}{|c|}{ ADL evolution $(n=387)$} \\
\hline & $\begin{array}{l}\text { Improvement } \\
\text { n (\%) }\end{array}$ & $\begin{array}{l}\text { Stable } \\
\text { n (\%) }\end{array}$ & $\begin{array}{l}\text { Decline } \\
\text { n (\%) }\end{array}$ \\
\hline Breastcancer $(n=95)$ & $11(11.58)$ & $66(69.47)$ & $18(18.95)$ \\
\hline Colorectal cancer $(n=95)$ & $16(16.85)$ & $64(67.37)$ & $15(15.79)$ \\
\hline Prostate cancer $(n=16)$ & $3(18.75)$ & $12(75.00)$ & $1(6.25)$ \\
\hline Ovarian cancer $(n=43)$ & $5(11.63)$ & $25(58.14)$ & $13(30.23)$ \\
\hline Lungcancer $(\mathrm{n}=38)$ & $0(0)$ & $28(73.68)$ & $10(26.32)$ \\
\hline \multirow[t]{3}{*}{ Hematologic malignancy $(n=100)$} & $9(9.00)$ & $71(71.00)$ & $20(20.00)$ \\
\hline & \multicolumn{3}{|c|}{ IADL evolution $(n=387)$} \\
\hline & $\begin{array}{l}\text { Improvement } \\
\text { n (\%) }\end{array}$ & $\begin{array}{l}\text { Stable } \\
\text { n (\%) }\end{array}$ & $\begin{array}{l}\text { Decline } \\
\text { n (\%) }\end{array}$ \\
\hline Breastcancer $(\mathrm{n}=95)$ & $21(22.11)$ & $28(29.47)$ & $46(48.42)$ \\
\hline Colorectal cancer $(\mathrm{n}=95)$ & $17(17.90)$ & $50(52.63)$ & $28(29.47)$ \\
\hline Prostate cancer $(n=16)$ & $3(18.75)$ & $8(50.00)$ & $5(31.25)$ \\
\hline Ovarian cancer $(n=43)$ & $12(27.91)$ & $12(27.91)$ & $19(44.19)$ \\
\hline Lungcancer $(\mathrm{n}=38)$ & $4(10.53)$ & $14(36.84)$ & $20(52.63)$ \\
\hline Hematologic malignancy $(n=100)$ & $15(15.00)$ & $43(43.00)$ & $42(42.00)$ \\
\hline
\end{tabular}

Legend: $\mathrm{ADL}=$ Activities of Daily Living; IADL = Instrumental Activities of Daily Living.

\section{Appendix B. Evolution of functional status related to tumor type and staging of the tumor}

\begin{tabular}{|c|c|c|c|c|}
\hline & & \multicolumn{3}{|c|}{ ADL evolution $(n=387)$} \\
\hline & & $\begin{array}{l}\text { Improvement } \\
\text { n (\%) }\end{array}$ & $\begin{array}{l}\text { Stable } \\
\text { n (\%) }\end{array}$ & $\begin{array}{l}\text { Decline } \\
\text { n (\%) }\end{array}$ \\
\hline \multirow{4}{*}{$\begin{array}{l}\text { Breastcancer } \\
\qquad(\mathrm{n}=95)\end{array}$} & Stage I $(\mathrm{n}=2)$ & $0(0)$ & $2(2.11)$ & $0(0)$ \\
\hline & Stage II $(n=26)$ & $4(4.21)$ & $20(21.05)$ & $2(2.11)$ \\
\hline & Stage III $(n=20)$ & $2(2.11)$ & $14(14.74)$ & $4(4.21)$ \\
\hline & Stage IV $(n=47)$ & $5(5.26)$ & $30(31.58)$ & $12(12.63)$ \\
\hline \multirow{4}{*}{$\begin{array}{l}\text { Colorectal } \\
\text { cancer }(n=95)\end{array}$} & Stage I $(n=1)$ & $0(0)$ & $1(1.05)$ & $0(0)$ \\
\hline & Stage II $(n=5)$ & $1(1.05)$ & $4(4.21)$ & $0(0)$ \\
\hline & Stage III $(\mathrm{n}=12)$ & $1(1.05)$ & $8(8.42)$ & $3(3.16)$ \\
\hline & Stage IV $(\mathrm{n}=77)$ & $14(14.74)$ & $51(53.68)$ & $12(12.63)$ \\
\hline \multirow{4}{*}{$\begin{array}{l}\text { Prostate } \\
\quad \text { cancer }(n=16)\end{array}$} & Stage I $(\mathrm{n}=0)$ & $0(0)$ & $0(0)$ & $0(0)$ \\
\hline & Stage II $(\mathrm{n}=0)$ & $0(0)$ & $0(0)$ & $0(0)$ \\
\hline & Stage III $(n=0)$ & $0(0)$ & $0(0)$ & $0(0)$ \\
\hline & Stage IV $(n=3)$ & $3(18.75)$ & $12(75.00)$ & $1(6.25)$ \\
\hline \multirow{4}{*}{$\begin{array}{l}\text { Ovarian } \\
\quad \text { cancer }(n=43)\end{array}$} & Stage I $(n=2)$ & $2(4.65)$ & $0(0)$ & $0(0)$ \\
\hline & Stage II $(\mathrm{n}=1)$ & $0(0)$ & $0(0)$ & $1(2.33)$ \\
\hline & Stage III $(\mathrm{n}=20)$ & $2(4.65)$ & $13(30.23)$ & $5(11.63)$ \\
\hline & Stage IV $(\mathrm{n}=20)$ & $1(2.33)$ & $12(27.91)$ & $7(16.28)$ \\
\hline \multirow{4}{*}{$\begin{array}{l}\text { Lungcancer } \\
\qquad(\mathrm{n}=38)\end{array}$} & Stage I $(\mathrm{n}=0)$ & $0(0)$ & $0(0)$ & $0(0)$ \\
\hline & Stage II $(\mathrm{n}=1)$ & $0(0)$ & $1(2.63)$ & $0(0)$ \\
\hline & Stage III $(\mathrm{n}=7)$ & $0(0)$ & $7(18.42)$ & $0(0)$ \\
\hline & Stage IV $(\mathrm{n}=30)$ & $0(0)$ & $20(52.63)$ & $10(26.32)$ \\
\hline \multirow{3}{*}{$\begin{array}{l}\text { Hematologic } \\
\text { malignancy } \\
(n=100)\end{array}$} & & $9(9.00)$ & $71(71.00)$ & $20(20.00)$ \\
\hline & & \multicolumn{3}{|c|}{ IADL evolution $(n=387)$} \\
\hline & & $\begin{array}{l}\text { Improvement } \\
\text { n (\%) }\end{array}$ & $\begin{array}{l}\text { Stable } \\
\text { n (\%) }\end{array}$ & $\begin{array}{l}\text { Decline } \\
\text { n (\%) }\end{array}$ \\
\hline \multirow{4}{*}{$\begin{array}{l}\text { Breastcancer } \\
\quad(n=95)\end{array}$} & Stage I $(\mathrm{n}=2)$ & $0(0)$ & $2(2.11)$ & $0(0)$ \\
\hline & Stage II $(n=26)$ & $5(5.26)$ & $8(8.42)$ & $13(13.68)$ \\
\hline & Stage III $(\mathrm{n}=20)$ & $4(4.21)$ & $4(4.21)$ & $12(12.63)$ \\
\hline & Stage IV $(n=47)$ & $12(12.63)$ & $14(14.74)$ & 21 (22.11) \\
\hline
\end{tabular}

Appendix B (continued)

\begin{tabular}{|c|c|c|c|c|}
\hline & & \multicolumn{3}{|c|}{ IADL evolution $(n=387)$} \\
\hline & & $\begin{array}{l}\text { Improvement } \\
\text { n (\%) }\end{array}$ & $\begin{array}{l}\text { Stable } \\
\text { n (\%) }\end{array}$ & $\begin{array}{l}\text { Decline } \\
\text { n (\%) }\end{array}$ \\
\hline \multirow{4}{*}{$\begin{array}{l}\text { Colorectal } \\
\text { cancer }(n=95)\end{array}$} & Stage I $(n=1)$ & $1(1.05)$ & $0(0)$ & $0(0)$ \\
\hline & Stage II $(n=5)$ & $3(3.16)$ & $2(2.11)$ & $0(0)$ \\
\hline & Stage III $(\mathrm{n}=12)$ & $2(2.11)$ & $7(51.58)$ & $3(3.16)$ \\
\hline & Stage IV $(n=77)$ & $11(11.58)$ & $41(43.16)$ & $25(26.32)$ \\
\hline \multirow{4}{*}{$\begin{array}{l}\text { Prostate } \\
\quad \text { cancer }(n=16)\end{array}$} & Stage I $(\mathrm{n}=0)$ & $0(0)$ & $0(0)$ & $0(0)$ \\
\hline & Stage II $(\mathrm{n}=0)$ & $0(0)$ & $0(0)$ & $0(0)$ \\
\hline & Stage III $(\mathrm{n}=0)$ & $0(0)$ & $0(0)$ & $0(0)$ \\
\hline & Stage IV $(n=3)$ & $3(18.75)$ & $8(50.00)$ & $5(31.25)$ \\
\hline \multirow{4}{*}{$\begin{array}{l}\text { Ovarian } \\
\quad \text { cancer }(n=43)\end{array}$} & Stage I $(n=2)$ & $0(0)$ & $0(0)$ & $2(4.65)$ \\
\hline & Stage II $(\mathrm{n}=1)$ & $0(0)$ & $0(0)$ & $1(2.33)$ \\
\hline & Stage III $(\mathrm{n}=20)$ & $5(11.63)$ & $7(16.28)$ & $8(18.60)$ \\
\hline & Stage IV $(n=20)$ & $7(16.28)$ & $5(11.63)$ & $8(18.60)$ \\
\hline \multirow{4}{*}{$\begin{array}{l}\text { Lungcancer } \\
\qquad(\mathrm{n}=38)\end{array}$} & Stage I $(\mathrm{n}=0)$ & $0(0)$ & $0(0)$ & $0(0)$ \\
\hline & Stage II $(\mathrm{n}=1)$ & $1(2.63)$ & $0(0)$ & $0(0)$ \\
\hline & Stage III $(\mathrm{n}=7)$ & $0(0)$ & $4(10.53)$ & $3(7.89)$ \\
\hline & Stage IV $(n=30)$ & $3(7.89)$ & $10(26.32))$ & $17(44.74)$ \\
\hline $\begin{array}{l}\text { Hematologic } \\
\text { malignancy } \\
(n=100)\end{array}$ & & $15(15.00)$ & $43(43.00)$ & $42(42.00)$ \\
\hline
\end{tabular}

Legend: $\mathrm{ADL}=$ Activities of Daily Living; $\mathrm{IADL}=$ Instrumental Activities of Daily Living.

\section{References}

[1] Burhenn PS, McCarthy AL, Begue A, Nightingale G, Cheng K, Kenis C. Geriatric assessment in daily oncology practice for nurses and allied health care professionals: Opinion paper of the Nursing and Allied Health Interest Group of the International Society of Geriatric Oncology (SIOG). J Geriatr Oncol 2016;7(5):315-24.

[2] Repetto L, Fratino L, Audisio RA, Venturino A, Gianni W, Vercelli M, et al. Comprehensive geriatric assessment adds information to Eastern Cooperative Oncology Group performance status in elderly cancer patients: an Italian Group for Geriatric Oncology Study. J Clin Oncol 2002;20(2):494-502.

[3] Wedding U, Rohrig B, Klippstein A, Pientka L, Hoffken K. Age, severe comorbidity and functional impairment independently contribute to poor survival in cancer patients. J Cancer Res Clin Oncol 2007;133(12):945-50.

[4] Jordhoy MS, Fayers P, Loge JH, Saltnes T, Ahlner-Elmqvist M, Kaasa S. Quality of life in advanced cancer patients: the impact of sociodemographic and medical characteristics. Br J Cancer 2001;85(10):1478-85.

[5] Yates JW, Chalmer B, McKegney FP. Evaluation of patients with advanced cancer using the Karnofsky performance status. Cancer 1980;45(8):2220-4.

[6] Oken MM, Creech RH, Tormey DC, Horton J, Davis TE, Mcfadden ET, et al. Toxicity and response criteria of the Eastern-Cooperative-Oncology-Group. Am J Clin Oncol Cancer Clin Trials 1982;5(6):649-55.

[7] Wildiers H, Heeren P, Puts M, Topinkova E, Janssen-Heijnen ML, Extermann M, et al. International Society of Geriatric Oncology consensus on geriatric assessment in older patients with cancer. J Clin Oncol 2014;32(24):2595-603.

[8] Katz S, Ford AB, Moskowitz RW, Jackson BA, Jaffe MW. Studies of illness in the aged. The index of ADL: a standardized measure of biological and psychosocial function. JAMA 1963;185:914-9.

[9] Lawton MP, Brody EM. Assessment of older people: self-maintaining and instrumental activities of daily living. Gerontologist 1969;9(3):179-86.

[10] Stuck AE, Siu AL, Wieland GD, Adams J, Rubenstein LZ. Comprehensive geriatric assessment - a metaanalysis of controlled trials. Lancet 1993;342(8878):1032-6.

[11] Pallis AG, Wedding $U$, Lacombe D, Soubeyran P, Wildiers $H$. Questionnaires and instruments for a multidimensional assessment of the older cancer patient: what clinicians need to know? Eur J Cancer 2010;46(6):1019-25.

[12] Rubenstein LZ, Stuck AE, Siu AL, Wieland D. Impacts of geriatric evaluation and management programs on defined outcomes: overview of the evidence. J Am Geriatr Soc 1991;39(9 Pt 2):8S-16S [discussion 7S-8S]

[13] Hoogerduijn JG, Schuurmans MJ, Korevaar JC, Buurman BM, de Rooij SE. Identification of older hospitalised patients at risk for functional decline, a study to compare the predictive values of three screening instruments. I Clin Nurs 2010;19(9-10):1219-25.

[14] Covinsky KE, Justice AC, Rosenthal GE, Palmer RM, Landefeld CS. Measuring prognosis and case mix in hospitalized elders. The importance of functional status. J Gen Intern Med 1997;12(4):203-8.

[15] Fortinsky RH, Covinsky KE, Palmer RM, Landefeld CS. Effects of functional status changes before and during hospitalization on nursing home admission of older adults. J Gerontol A Biol Sci Med Sci 1999;54(10):M521-6.

[16] Rudberg MA, Sager MA, Zhang J. Risk factors for nursing home use after hospitalization for medical illness. J Gerontol A Biol Sci Med Sci 1996;51(5):M189-94.

[17] Maccormick RE. Possible acceleration of aging by adjuvant chemotherapy: a cause of early onset frailty? Med Hypotheses 2006;67(2):212-5.

[18] Versteeg KS, Konings IR, Lagaay AM, van de Loosdrecht AA, Verheul HM. Prediction of treatment-related toxicity and outcome with geriatric assessment in elderly patients with solid malignancies treated with chemotherapy: a systematic review. Ann Oncol 2014;25(10):1914-8.

[19] Puts MTE, Monette J, Girre V, Wolfson C, Monette M, Batist G, et al. Changes in functional status in older newly-diagnosed cancer patients during cancer treatment: 
a six-month follow-up period. Results of a prospective pilot study. J Geriatr Oncol 2011;2(2):112-20.

[20] Balducci L, Stanta G. Cancer in the frail patient. A coming epidemic. Hematol Oncol Clin North Am 2000;14(1):235-50 [xi].

[21] Arnold M, Karim-Kos HE, Coebergh JW, Byrnes G, Antilla A, Ferlay J, et al. Recent trends in incidence of five common cancers in 26 European countries since 1988: analysis of the European cancer observatory. Eur J Cancer 2015;51(9):1164-87.

[22] Smith BD, Smith GL, Hurria A, Hortobagyi GN, Buchholz TA. Future of cancer incidence in the United States: burdens upon an aging, changing nation. J Clin Oncol 2009;27(17):2758-65.

[23] McCusker J, Kakuma R, Abrahamowicz M. Predictors of functional decline in hospitalized elderly patients: a systematic review. J Gerontol A Biol Sci Med Sci 2002;57(9):M569-77.

[24] Kenis C, Decoster L, Van Puyvelde K, De Greve J, Conings G, Milisen K, et al. Performance of two geriatric screening tools in older patients with cancer. J Clin Oncol 2014;32(1): $19-26$.

[25] Braes T, Flamaing J, Sterckx W, Lipkens P, Sabbe M, de Rooij SE, et al. Predicting the risk of functional decline in older patients admitted to the hospital: a comparison of three screening instruments. Age Ageing 2009;38(5):600-3.

[26] Meldon SW, Mion LC, Palmer RM, Drew BL, Connor JT, Lewicki LJ, et al. A brief riskstratification tool to predict repeat emergency department visits and hospitalizations in older patients discharged from the emergency department. Acad Emerg Med 2003;10(3):224-32.

[27] Soubeyran P, Bellera C, Goyard J, Heitz D, Cure H, Rousselot H, et al. Validation of the G8 screening tool in geriatric oncology: the ONCODAGE project. ASCO annual meeting 2011: Chicago. J Clin Oncol 2011:29 (suppl; abstr 9001).

[28] Bellera CA, Rainfray M, Mathoulin-Pelissier S, Mertens C, Delva F, Fonck M, et al. Screening older cancer patients: first evaluation of the G-8 geriatric screening tool. Ann Oncol 2012;23(8):2166-72.

[29] Lamb SE, Jorstad-Stein EC, Hauer K, Becker C. Development of a common outcome data set for fall injury prevention trials: the prevention of Falls Network Europe consensus. J Am Geriatr Soc 2005;53(9):1618-22.

[30] Tinetti ME, Speechley M, Ginter SF. Risk factors for falls among elderly persons living in the community. N Engl J Med 1988;319(26):1701-7.

[31] Folstein MF, Folstein SE, McHugh PR. "Mini-mental state". A practical method for grading the cognitive state of patients for the clinician. J Psychiatr Res 1975;12(3): 189-98.

[32] Yesavage JA, Brink TL, Rose TL, Lum O, Huang V, Adey M, et al. Development and validation of a geriatric depression screening scale: a preliminary report. J Psychiatr Res 1982;17(1):37-49.

[33] Rubenstein LZ, Harker JO, Salva A, Guigoz Y, Vellas B. Screening for undernutrition in geriatric practice: developing the short-form mini-nutritional assessment (MNASF). J Gerontol A Biol Sci Med Sci 2001:56(6):M366-72.

[34] Vellas B, Guigoz Y, Garry PJ, Nourhashemi F, Bennahum D, Lauque S, et al. The mini nutritional assessment (MNA) and its use in grading the nutritional state of elderly patients. Nutrition 1999;15(2):116-22.

[35] Charlson ME, Pompei P, Ales KL, MacKenzie CR. A new method of classifying prognostic comorbidity in longitudinal studies: development and validation. J Chronic Dis 1987;40(5):373-83.

[36] Avlund K, Holstein BE. Functional ability among elderly people in three service settings: the discriminatory power of a new functional ability scale. Eur J Epidemiol 1998;14(8):783-90.

[37] Collins SL, Moore RA, McQuay HJ. The visual analogue pain intensity scale: what is moderate pain in millimetres? Pain 1997:72(1-2):95-7.

[38] Deschodt M, Wellens NI, Braes T, De VA, Boonen S, Flamaing J, et al. Prediction of functional decline in older hospitalized patients: a comparative multicenter study of three screening tools. Aging Clin Exp Res 2011:23(5-6):421-6.

[39] Geyskens K, De RK, Sabbe M, Braes T, Milisen K, Flamaing J, et al. Prediction of functional decline in elderly patients discharged from the accident and emergency department. Tijdschr Gerontol Geriatr 2008;39(1):16-25.
[40] Aliamus V, Adam C, Druet-Cabanac M, Dantoine T, Vergnenegre A. Geriatric assessment contribution to treatment decision-making in thoracic oncology. Rev Mal Respir 2011;28(9):1124-30.

[41] Hamaker ME, Vos AG, Smorenburg CH, de Rooij SE, van Munster BC. The value of geriatric assessments in predicting treatment tolerance and all-cause mortality in older patients with cancer. Oncologist 2012;17(11):1439-49.

[42] Kenis C, Bron D, Libert Y, Decoster L, Van Puyvelde K, Scalliet P, et al. Relevance of a systematic geriatric screening and assessment in older patients with cancer: results of a prospective multicentric study. Ann Oncol 2013;24(5):1306-12.

[43] Klepin HD, Geiger AM, Tooze JA, Kritchevsky SB, Williamson JD, Ellis LR, et al. The feasibility of inpatient geriatric assessment for older adults receiving induction chemotherapy for acute myelogenous leukemia. J Am Geriatr Soc 2011;59(10):1837-46.

[44] Maione P, Perrone F, Gallo C, Manzione L, Piantedosi F, Barbera S, et al. Pretreatment quality of life and functional status assessment significantly predict survival of elderly patients with advanced non-small-cell lung cancer receiving chemotherapy: a prognostic analysis of the multicenter Italian lung cancer in the elderly study. J Clin Oncol 2005;23(28):6865-72.

[45] Puts M, Hardt J, Monette J, Girre V, Springall E, Alibhai SM. A systematic review of the use of geriatric assessment for older adults in oncology. Gerontologist 2012; 52:629.

[46] Soubeyran P, Fonck M, Blanc-Bisson C, Blanc JF, Ceccaldi J, Mertens C, et al. Predictors of early death risk in older patients treated with first-line chemotherapy for cancer. J Clin Oncol 2012;30(15):1829-34.

[47] Hoppe S, Rainfray M, Fonck M, Hoppenreys L, Blanc JF, Ceccaldi J, et al. Functional decline in older patients with cancer receiving first-line chemotherapy. J Clin Oncol 2013;31(31):3877-82.

[48] Ronning B, Wyller TB, Jordhoy MS, Nesbakken A, Bakka A, Seljeflot I, et al. Frailty indicators and functional status in older patients after colorectal cancer surgery. J Geriatr Oncol 2014;5(1):26-32.

[49] Deckx L, van den Akker M, Daniels L, De Jonge ET, Bulens P, Tjan-Heijnen VC, et al, Geriatric screening tools are of limited value to predict decline in functional status and quality of life: results of a cohort study. BMC Fam Pract 2015;16:30.

[50] Dent E, Visvanathan R, Piantadosi C, Chapman I. Nutritional screening tools as predictors of mortality, functional decline, and move to higher level care in older people: a systematic review. J Nutr Gerontol Geriatr 2012;31(2):97-145.

51] Kiesswetter E, Pohlhausen S, Uhlig K, Diekmann R, Lesser S, Uter W, et al. Prognostic differences of the mini nutritional assessment short form and long form in relation to 1-year functional decline and mortality in community-dwelling older adults receiving home care. J Am Geriatr Soc 2014;62(3):512-7.

[52] Covinsky KE, Palmer RM, Fortinsky RH, Counsell SR, Stewart AL, Kresevic D, et al. Loss of independence in activities of daily living in older adults hospitalized with medical illnesses: increased vulnerability with age. J Am Geriatr Soc 2003;51(4):451-8.

[53] Cornette P, Swine C, Malhomme B, Gillet JB, Meert P, D'Hoore W. Early evaluation of the risk of functional decline following hospitalization of older patients: development of a predictive tool. Eur J Public Health 2006;16(2):203-8.

[54] Freyer G, Geay JF, Touzet S, Provencal J, Weber B, Jacquin JP, et al. Comprehensive geriatric assessment predicts tolerance to chemotherapy and survival in elderly patients with advanced ovarian carcinoma: a GINECO study. Ann Oncol 2005;16(11): 1795-800.

[55] Gironés R, Torregrosa D, Maestu I, Gómez-Codina J, Tenias JM, Costa RR. Comprehensive geriatric assessment (CGA) of elderly lung cancer patients: a single-center experience. J Geriatr Oncol 2012;3(2):98-103.

[56] Buurman BM, van Munster BC, Korevaar JC, de Haan RJ, de Rooij SE. Variability in measuring (instrumental) activities of daily living functioning and functional decline in hospitalized older medical patients: a systematic review. J Clin Epidemiol 2011; 64(6):619-27. 